Bangladesh Journal of Anatomy July 2009, Vol. 7 No. 2 pp. 109-116

\title{
Internal Diameter of the Main Pancreatic Duct - A Post Mortem Study
}

\author{
Sunjida Shahriah ${ }^{1}$, Md. Shameem Ahmed ${ }^{2}$, Md. Jahangir Alam ${ }^{3}$, Khandaker Abu Rayhan ${ }^{4}$,
} Abu Sadat Mohammad Nurunnabi ${ }^{5}$, Gul Newaz Begum ${ }^{6}$, Rukshana Ahmed ${ }^{7}$, Shamim Ara ${ }^{8}$

\begin{abstract}
Context: Main pancreatic duct is an important vessel for transport of pancreatic exocrine secretion. It gradually tapers towards the tail. Progressive narrowing of the internal diameter of the main pancreatic duct is dangerous for removal of pancreatic or dislodged gallbladder calculi.
\end{abstract}

Study design: A descriptive type of study.

Place and period of study: The study was carried out in the Department of Anatomy, Dhaka Medical College, from August 2005 to December 2006.

Materials: The present study was performed on 75 male humans. The samples were collected from the unclaimed dead bodies within 24 hours after death that were under examination in the Department of Forensic Medicine of Dhaka Medical College, Dhaka.

Method: The samples were divided into 7 different age groups and comparative studies were made between different groups. All samples were studied morphologically. Internal diameter of the main pancreatic duct was measured at four points with the help of a dissecting microscope.

Result: Internal diameter of the main pancreatic duct increased progressively with age, which showed positive correlation and was statistically significant $(P<0.001)$.

Conclusion: Further studies with large sample in both sexes, comparison of internal diameter of main pancreatic duct with in situ X-ray, corrosion cast of the pancreatic ductal system, pancreatic ductal histological studies are recommended.

Key words: Main pancreatic duct, internal diameter.

\section{Introduction:}

Main pancreatic duct was described by Wirsung in $1642^{1}$. It arises in tail of the pancreas; receives lobular ducts, joining at the right angles (herringbone

1. Assistant Professor, Department of Anatomy. Chattagram Ma-O-Shishu Hospital and Medical College, Chittagong.

2. Associate Professor and Head of the Department of Anatomy. Central Medical College, Comilla.

3. Assistant Professor (cc), Department of Anatomy. Sir Sallimullah Medical College. Dhaka.

4. Assistant Professor, Department of Anatomy. Southern Medical College. Chittagong.

5. Medical Officer, Union Sub-Centre, Shampur, Islampur, Jamalpur.

6. Associate Professor, Department of Anatomy. Anwer Khan Modern Medical College, Dhaka

7. Lecturer, Department of Anatomy. Dhaka Medical College. Dhaka.

8. Professor and Head, Department of Anatomy. Dhaka Medical College. Dhaka.

Correspondence: Dr. Sunjida Shahriah pattern) running towards the common bile duct. It may or may not join the common bile duct and drains upper part of the head, body and tail of the gland ${ }^{2}$. Usually opens at the major duodenal papilla.

A full understanding of the caliber of the main pancreatic duct is essential for any surgeon operating on the pancreas. Variations in the internal diameter of the main pancreatic duct are dangerous for removal of pancreatic or dislodged gallbladder calculi ${ }^{3}$. This makes difficulties in removal of the calculi within the duct and in ERCP (Endoscopic Retrograde cholangio pancreatiogram) canulation. In case of measurement of the intraductal pressure following injection of contrast material, the diameter of the main pancreatic duct ${ }^{3}$ is directly related with the pressure with in them.

\section{Materials and methods:}

The present study was performed on 75 male pancreas in different age groups of Bangladeshi 
people. The study was done from August 2005 to December 2006.

Pancreas, stomach and duodenum were taken en block. Duodenum was separated from the stomach and jejunum. Lateral end of the duodenum was incised. The cleaned specimen was fixed with $10 \%$ formol saline in a labeled jar for 48 hours. This fixed specimen was easier for further fine dissection. After 48 hours, the site of entry of the main pancreatic duct into the duodenum with or with out association of common bile duct was identified by palpation ${ }^{4}$. Adjoining fascia between the c-shaped curvature of duodenum and pancreas was excised after presenving external part of main pancreatic duct, minor pancreatic duct \{if present\} and common bile duct. Then following the main pancreatic duct; on the posterior surface of the pancreas, the lobules were picked away in piecemeal (Fig.-1) and total ductal system including main pancreatic duct, accessory pancreatic duct and common bile duct were completely separated from the pancreatic soft tissue by keeping the communication with duodenum ${ }^{5}$ (Fig.-2).

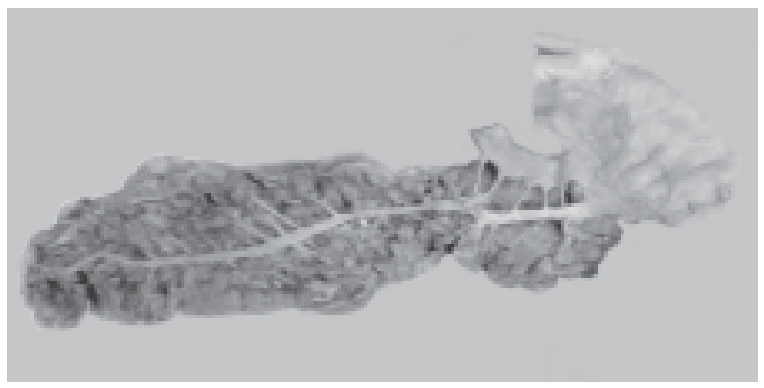

Fig.-1: Pancreatic ductal system in situ.

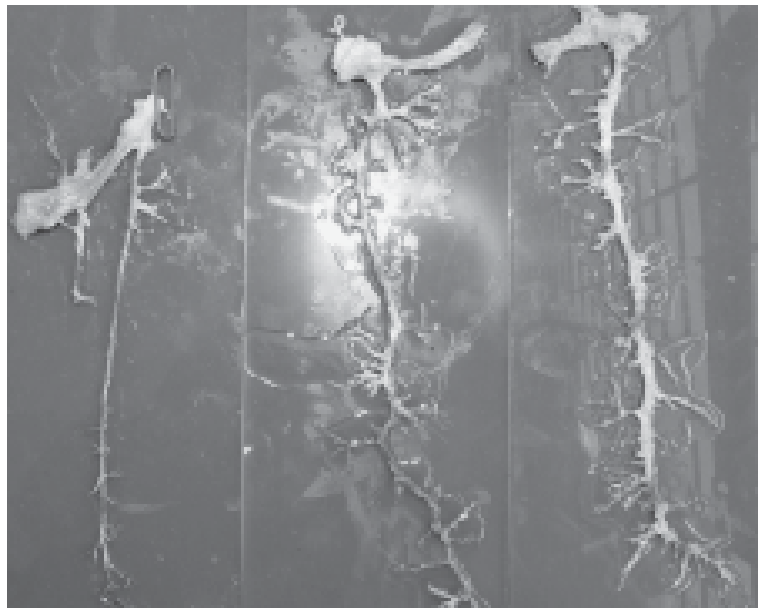

Fig.-2: Pancreatic ductal system after total removal of soft tissue.
Grouping of the samples:

The collected samples were divided into seven group $(A, B, C, D, E, F, G)^{6}$

Table-I

Grouping of the samples in relation to age.

\begin{tabular}{cc}
\hline Group & Age limit in years \\
\hline A & $10-19$ \\
B & $20-29$ \\
C & $30-39$ \\
D & $40-49$ \\
E & $50-59$ \\
F & $60-69$ \\
G & 70 and above 70 \\
\hline
\end{tabular}

Parameters:

Internal diameter of the main pancreatic duct was measured;

i. At 1 inch proximal to the commencement of the tail of the pancreas.

ii. Apparently mid portion of the body region.

iii. Just entering at the head.

iv. Prior to join the common bile duct in case of a common opening, or

v. Prior to open at the duodenum in case of individual opening.

\section{Procedure of the study:}

Internal diameter of the main pancreatic duct was measured with the help of a dissecting microscope. At first $1 \mathrm{~mm}$ was subdivided into 10 times (0.10 $\mathrm{mm}$ ) by Visio basic soft ware 2000 version. This print was taken on a transparency sheet and cut into a little bit smaller pieces than a histology glass slide. Now the separated main pancreatic duct was cut transversely with scissor as thin as possible starting from the extreme end i.e. at the 1 inches proximal to the commencement of the tail and apparently mid portion of body region, subsequently just entering at head, lastly prior to join the common bile duct in case of a common opening or prior to open at the duodenum in case of individual opening. The cut sections were placed on a slide placed over the cut piece of the transparency sheet and put under the dissecting microscope (Fig.-3). The internal diameter (i.e. the inner aspect of the lumen) was counted that how many distance was crossed in the scale and expressed in fractions of $\mathrm{mm}^{7}$. 


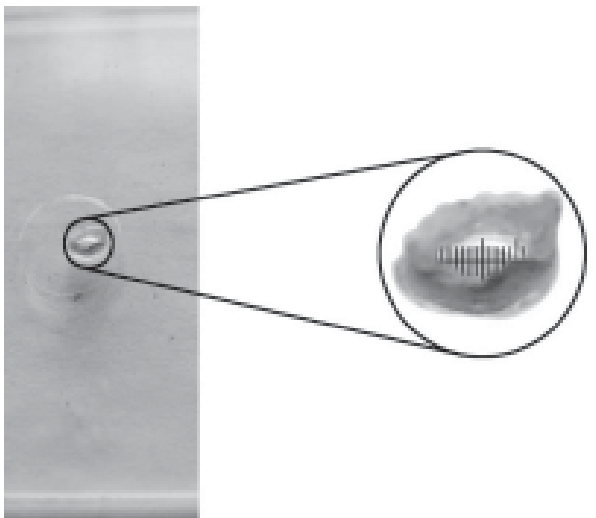

Fig.-3: Measurement of internal diameter of the main pancreatic duct.

\section{Results:}

Internal diameter of the main pancreatic duct in the head, body and tail:

Internal diameter of the main pancreatic duct in the head, body and tail is shown in table Ila and IIb, figure: 1 .

Table - Ila

Internal diameter of main pancreatic duct (MPD) in the head, body and tail of different study group

\begin{tabular}{lcccc}
\hline & & \multicolumn{3}{c}{ Internal diameter of MPD $(\mathrm{mm})$} \\
\cline { 3 - 5 } Group & $\mathrm{n}$ & Head & Body & Tail \\
& & Mean \pm SD & Mean \pm SD & Mean \pm SD \\
\hline A & 6 & $2.65 \pm 0.31$ & $2.07 \pm 0.27$ & $1.40 \pm 0.48$ \\
& & $(2.2-3.0)$ & $(1.7-2.5)$ & $(0.8-2.0)$ \\
B & 17 & $3.49 \pm 0.38$ & $2.81 \pm 0.39$ & $2.17+0.45$ \\
& & $(2.9-4.0)$ & $(2.1-3.6)$ & $(1.6-2.9)$ \\
C & 14 & $3.59 \pm 0.22$ & $2.82 \pm 0.17$ & $1.96 \pm 0.27$ \\
& & $(3.2-3.9)$ & $(2.5-3.1)$ & $(1.6-2.6)$ \\
D & 1 & $3.89 \pm 0.19$ & $2.92 \pm 0.20$ & $223 \pm 0.28$ \\
& & $(3.7-4.3)$ & $(2.5-3.2)$ & $(2.0-2.8)$ \\
E & 7 & $4.31 \pm 0.36$ & $3.33 \pm 0.59$ & $2.54 \pm 0.63$ \\
& & $(3.7-4.7)$ & $(2.5-4.0)$ & $(1.8-3.5)$ \\
F & 5 & $4.40 \pm 0.35$ & $3.62 \pm 0.40$ & $2.76 \pm 0.34$ \\
& & $(4.0-4.8)$ & $(3.0-4.0)$ & $(2.3-3.1)$ \\
G & 5 & $4.56 \pm 0.28$ & $3.88 \pm 0.13$ & $2.98 \pm 0.31$ \\
& & $(4.1-4.8)$ & $(3.7-4.0)$ & $(2.5-3.3)$ \\
\hline
\end{tabular}

Figures in parentheses indicate range
Table Ilb

Statistical analysis for Table Ila

\begin{tabular}{|c|c|c|c|}
\hline Group & $\begin{array}{c}\text { Head } \\
\text { P value }\end{array}$ & $\begin{array}{c}\text { Body } \\
\text { P value }\end{array}$ & $\begin{array}{l}\text { Tail } \\
\text { P value }\end{array}$ \\
\hline$\overline{A v s ~ B}$ & $<0.001^{\star \star}$ & $<0.001^{\star \star}$ & $<0.001^{\star *}$ \\
\hline A vs C & $<0.001^{\star *}$ & $<0.001^{* *}$ & $<0.01^{\star *}$ \\
\hline$A$ vs D & $<0.001^{\star *}$ & $<0.001^{\star *}$ & $<0.001^{\star * *}$ \\
\hline$A$ vs $E$ & $<0.001$ & $<0.001^{\star *}$ & $<0.001^{\star *}$ \\
\hline A vs F & $<0.001$ & $<0.001^{* *}$ & $<0.001$ \\
\hline$A$ vs $G$ & $<0.001^{\star *}$ & $<0.001^{\star \star}$ & $<0.001^{\star *}$ \\
\hline$B$ vs $C$ & $>0.001$ & $>0.50 \mathrm{~ns}$ & $>0$. Ion, \\
\hline$B$ vs D & $<0.01^{\star \star}$ & $>0.10 \mathrm{~ns}$ & $>0.50^{\circ}$ \\
\hline$B$ vs $E$ & $<0.001^{\star \star \star}$ & $<0.01^{\star \star}$ & $<0.05^{\star}$ \\
\hline$B$ vs $F$ & $<0.001^{\star \star}$ & $<0.001^{\star \star}$ & $<0.01^{\star \star}$ \\
\hline$B$ vs $G$ & $<0.001^{\star *}$ & $<0.001^{* *}$ & $<0.001^{* *}$ \\
\hline Cvs D & $<0.05^{*}$ & $>0.001 \mathrm{~ns}$ & > 0.10"' \\
\hline C vs E & $<0.001^{\star *}$ & $<0.01^{\star \star}$ & $<0.01^{\star \star}$ \\
\hline C vs F & $<0.001^{\star \star}$ & $<0.001^{\star *}$ & $<0.001^{\star *}$ \\
\hline C vs G & $<0.001^{\star \star \star}$ & $<0.001^{\star *}$ & $<0.001^{* \star}$ \\
\hline D vs E & $<0.01^{* *}$ & $<0.05^{x}$ & $>0.10^{\prime \prime \prime}$ \\
\hline D vs F & $<0.01^{\star *}$ & $<0.001^{\star *}$ & $>0.001$ \\
\hline D vs G & $<0,001^{*}$ & $<0.001^{\star *} \star *$ & $>0.05 \mathrm{~ns}$ \\
\hline
\end{tabular}

Statistical analysis done by one-way ANOVA (PostHoc) test, ns $=$ not significant, ${ }^{* / \star * / \star \star \star}=$ significant

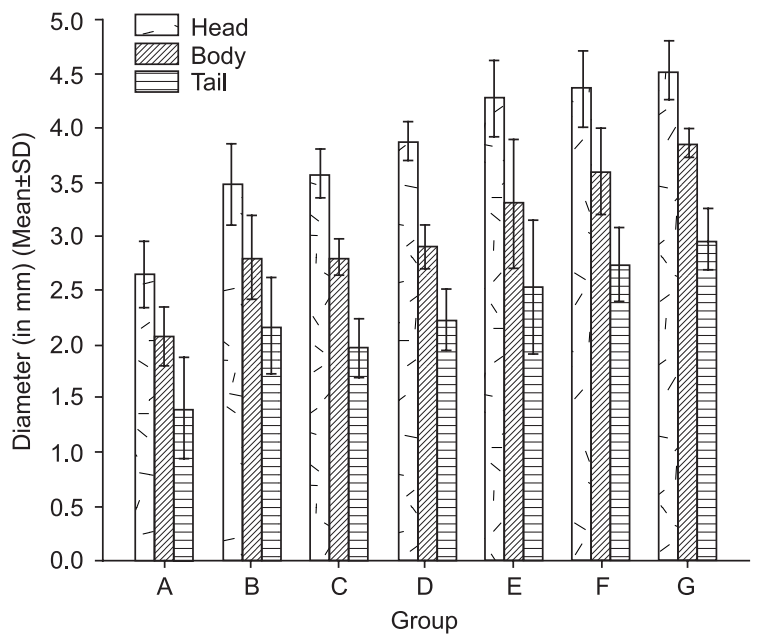

Figure-1: Internal diameter of main pancreatic duct (MPD) in head, body and tail in different age group 


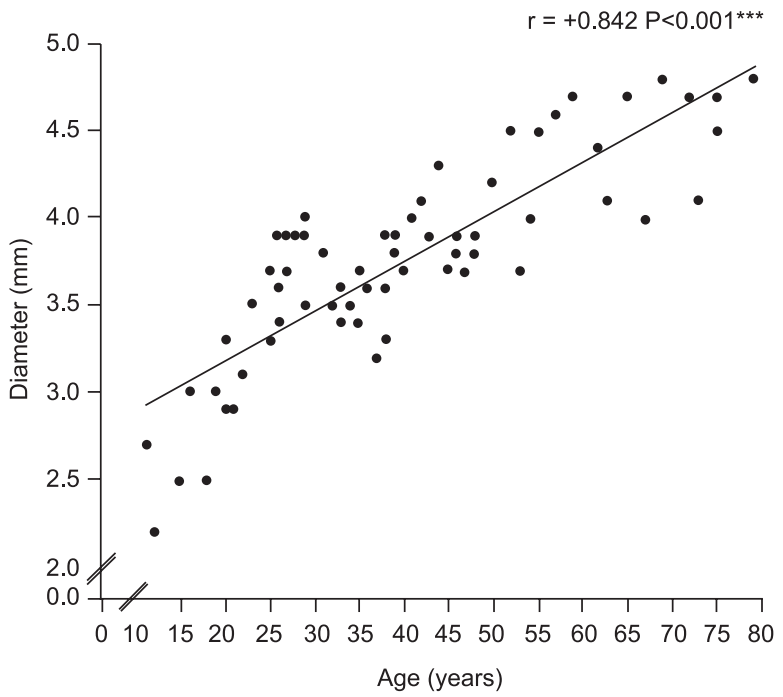

Fig-2a: Scatter diagram showing the relationship between age and internal diameter of the main pancreatic duct (MPD) in the head $(n=65)$

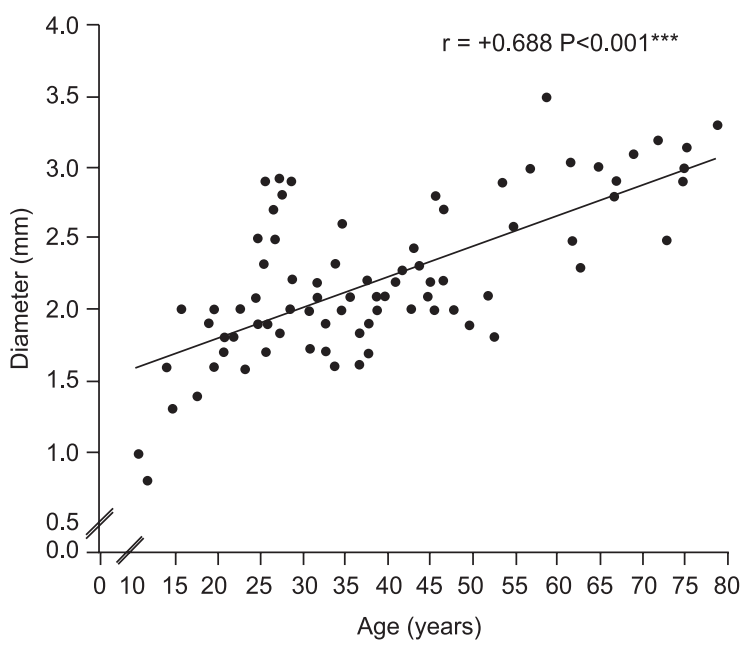

Fig-2c: Scatter diagram showing the relationship between age and internal diameter of the main pancreatic duct (MPD) in the tail $(n=65)$

Internal diameter of the main pancreatic duct in the head of the pancreas:

The highest mean internal diameter of the main pancreatic duct in the head was $4.56 \pm 0.28 \mathrm{~mm}$ in group G (70 and above years) and lowest was 2.65 $\pm 0.31 \mathrm{~mm}$ in group $\mathrm{A}$ (10 to 19 years). The difference

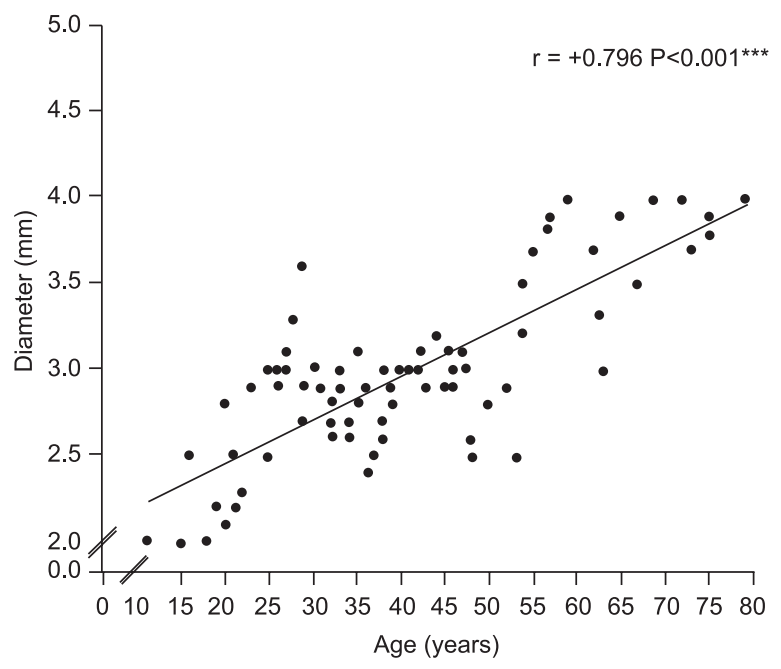

Fig-2b: Scatter diagram showing the relationship between age and internal diameter of the main pancreatic duct (MPD) in the body $(n=65)$

between the internal diameter of the main pancreatic duct in the head was statistically significant $(p<$ 0.001) in A vs B group, A vs C group, A vs D group, $A$ vs $E$ group, B vs $E$ group, B vs $F$ group, B vs $G$ group, C vs D group, C vs E group, C vs F group, $C$ vs $G$ group, $D$ vs $E$ group, $D$ vs $F$ group and $D$ vs $G$ group. The internal diameter of the main pancreatic duct in the head increased gradually with the advanced age. Figure: 2.a show the statistically significant $(p<0.001)$ positive correlation $(r=0.849)$ between age and internal diameter of the main pancreatic duct in the head of the pancreas.

Internal diameter of the main pancreatic duct in the body of the pancreas:

In the present study the highest internal diameter of the main pancreatic duct in the body was $2.92 \pm$ $0.20 \mathrm{~mm}$ in group $\mathrm{G}$ (70 and above years) and lowest was $2.07 \pm 0.27 \mathrm{~mm}$ in group A (10 to 19 years). The difference between the mean internal diameter of the main pancreatic duct in the body was statistically significant $(p<0.001)$ in A vs B group, $A$ vs $C$ group, A vs $D$ group, A vs $E$ group, $A$ vs $F$ group, A vs G group, B vs E group, B vs F group, B 
vs $G$ group, C vs E group, C vs F group, C vs G group, D vs $E$ group and $E$ vs $G$ group. The internal diameter of the main pancreatic duct in the body increased gradually with the advanced age. Figure: 2.b show the statistically significant $(p<0.001)$ positive correlation $(r=0.796)$ between age and internal diameter of the main pancreatic duct in the body of the pancreas.

Internal diameter of the main pancreatic duct in the tail of the pancreas:

The highest mean internal diameter of the main pancreatic duct in the tail was in group G (70 and above years) and the lowest was $1.40 \pm 0.48 \mathrm{~cm}$ in group A (10 to 19 years). The internal diameter of the main pancreatic duct in the tail show progressively increasing with advanced age. The difference between the internal diameter of the main pancreatic duct in the tail was statistically significant $(p<0.001)$ in A vs B group, A vs C group, A vs D group, A vs E group, A vs F group, A vs G group, B vs $E$ group, $B$ vs $F$ group, $B$ vs $G$ group, $C$ vs $E$ group, C vs F group, C vs G group and D vs E group. Figure: 2.c show the statistically significant $(p<$ $0.001)$ positive correlation $(r=0.688)$ between age and internal diameter of the main pancreatic duct in the tail of the pancreas.

The internal diameter of the main pancreatic duct in 63 specimens gradually tapered from head to the tail end. In 1 specimen the main pancreatic duct was of the same diameter in the head and body in Group C and in the 1 specimen in Group B, the diameter of main pancreatic duct was smaller in pancreatic head than body.

Internal diameter of the main pancreatic duct out side the pancreas (before joining the common bile duct or prior to independent opening at the duodenum):

Table IIIa and IIIb, Figure: 3 show the extra pancreatic part of the internal diameter of the main pancreatic duct out side the pancreas (before joining the common bile duct or prior to independent opening at the duodenum).
Table-IIla

Internal diameter of extra pancreatic part of main pancreatic duct (MPD) before joining common bile duct (CBD) and prior to independent opening at duodenurn in different study group

\begin{tabular}{|c|c|c|c|c|}
\hline \multirow[b]{3}{*}{ Group } & \multicolumn{4}{|c|}{ Internal diameter (mm) } \\
\hline & \multicolumn{2}{|c|}{$\begin{array}{l}\text { Prior to joining } \\
\text { CBD }\end{array}$} & \multicolumn{2}{|c|}{$\begin{array}{l}\text { Prior to independent } \\
\text { opening at duodenum }\end{array}$} \\
\hline & $\mathrm{n}$ & Mean \pm SD & $\mathrm{n}$ & Mean \pm SD \\
\hline$A$ & 2 & $\begin{array}{c}3.25 \pm 0.35 \\
(3.0-3.5)\end{array}$ & 4 & $\begin{array}{c}3.20 \pm 0.37 \\
(2.8-3.7)\end{array}$ \\
\hline B & 8 & $\begin{array}{c}4.09 \pm 0.32 \\
(3.5-4.5)\end{array}$ & 9 & $\begin{array}{c}4.28 \pm 0.37 \\
(3.6-4.8)\end{array}$ \\
\hline C & 7 & $\begin{array}{c}4,69 \pm 0.20 \\
(4.4-4.9)\end{array}$ & 7 & $\begin{array}{c}4.64 \pm 0.25 \\
(4.2-4.9)\end{array}$ \\
\hline$D$ & 5 & $\begin{array}{c}4.86 \pm 0.11 \\
(4.7-5.0)\end{array}$ & 6 & $\begin{array}{l}4.85 \pm 0.15 \\
(4.7-S .1)\end{array}$ \\
\hline $\mathrm{E}$ & 2 & $\begin{array}{c}5.20 \pm 0.14 \\
(5.1-5.3)\end{array}$ & 5 & $\begin{array}{r}5.12 \pm 0.19 \\
(4.9-5.4)\end{array}$ \\
\hline$F$ & 3 & $\begin{array}{c}5.40 \pm 0.10 \\
(5.3-5.5)\end{array}$ & 2 & $\begin{array}{c}5.15 \pm 0.07 \\
(51-5.2)\end{array}$ \\
\hline G & 2 & $\begin{array}{c}5.45 \pm 0.07 \\
(5.4-5.5)\end{array}$ & 3 & $\begin{array}{c}5.47 \pm 0.15 \\
(5.3-5.6)\end{array}$ \\
\hline
\end{tabular}

Figures in parentheses indicate range

Table IIIb

Statistical analysis for Table IIIa

\begin{tabular}{|c|c|c|}
\hline Group & $\mathrm{P}$ value & $P$ value \\
\hline$A$ vs $B$ & $<0.001$ ** & $<0.001^{* *}$ \\
\hline A vs C & $<0.001^{\star *}$ & $<0.001 * * "$ \\
\hline A vs D & $<0.001^{\prime \prime}$ & $<0.001^{* *}$ \\
\hline AvsE & $<0.001$ & $<0.001^{* *}$ \\
\hline Avs F & $<0.001^{*}$ & $<0.001^{* *}$ \\
\hline AvsG & $<0.001^{\star *}$ & $<0.001^{* *}$ \\
\hline B vs C & $<0.001^{\star *}$ & $<0.05^{\star}$ \\
\hline$B \vee s D$ & $<0.001^{*^{*}}$ & $<0.01^{\star *}$ \\
\hline B vs E & $<0.001^{\star *}$ & $<0.001^{*}$ \\
\hline B vs F & $<0.001^{\prime *}$ & $<0.001^{* *}$ \\
\hline$B$ vs $G$ & $<0.001^{\star *}$ & $<0.001^{* *}$ \\
\hline C vs D & > 0.10"' & $>0.10 " \mathrm{~s}$ \\
\hline C vs E & $<0.05^{\prime \prime}$ & $<0.01^{*}$ \\
\hline C vs F & $<0.001^{\star *}$ & $<0.05^{\prime \prime}$ \\
\hline C vs G & $<0.001^{\star \star}$ & $<0.001^{* *}$ \\
\hline D vs E & $>0.05 \mathrm{~ns}$ & $>0.10 \mathrm{~ns}$ \\
\hline $\mathrm{D}$ vs F & $<0.01^{\star *}$ & $>0.10^{\mathrm{ns}}$ \\
\hline D vs G & $<0.01 n s$ & $<0.01^{\star \star}$ \\
\hline Evs F & $>0.10 n s$ & $>0.50 n s$ \\
\hline E vs G & $>0.10 \mathrm{~ns}$ & $>0.10 n s$ \\
\hline F vs G & $>0.50 \mathrm{~ns}$ & $>0.10 n s$ \\
\hline
\end{tabular}

Statistical analysis done by one-way ANOVA (PostHoc)

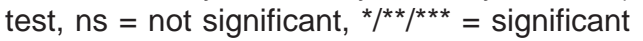




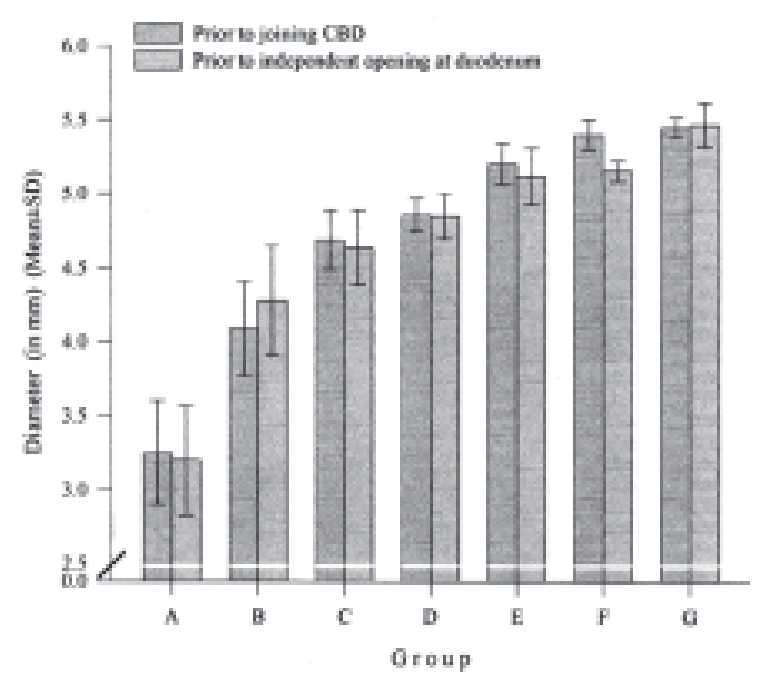

Figure-3: Internal diameter of extra pancreatic part of the main pancreatic duct (MPD) before joining the common bile duct or prior to independent opening in duodenum in different age group.

Internal diameter of the main pancreatic duct before joining the common bile duct:

The highest mean internal diameter of the main pancreatic duct before joining the common bile duct was in group G (70 and above70 years) and the lowest was in group $A$ (10 to 19 years). The difference between the internal diameter of the main pancreatic duct before joining the common bile duct was statistically significant $(p<0.001)$ in A vs B group, $A$ vs $C$ group, A vs $D$ group, $A$ vs $E$ group, $A$ vs $F$ group, A vs $G$ group, B vs E group, B vs $F$ group, B vs $G$ group, $C$ vs $E$ group, $C$ vs $F$ group, $C$ vs $G$ group and $D$ vs $E$ group. The internal diameter of the main pancreatic duct before joining the common bile duct gradually increased with the advancing age in the present study.

Internal diameter of the main pancreatic duct prior to independent opening at the duodenum: The highest mean internal diameter of the main pancreatic duct prior to independent opening at the duodenum was in group $\mathrm{G}$ (70 and above 70 years) and the lowest was in group $A$ (10 to 19 years). The difference between the internal diameter of the main pancreatic duct prior to independent opening at the duodenum was statistically significant $(p<0.001)$ in $A$ vs $B$ group, A vs $C$ group, A vs $D$ group, $A$ vs $E$

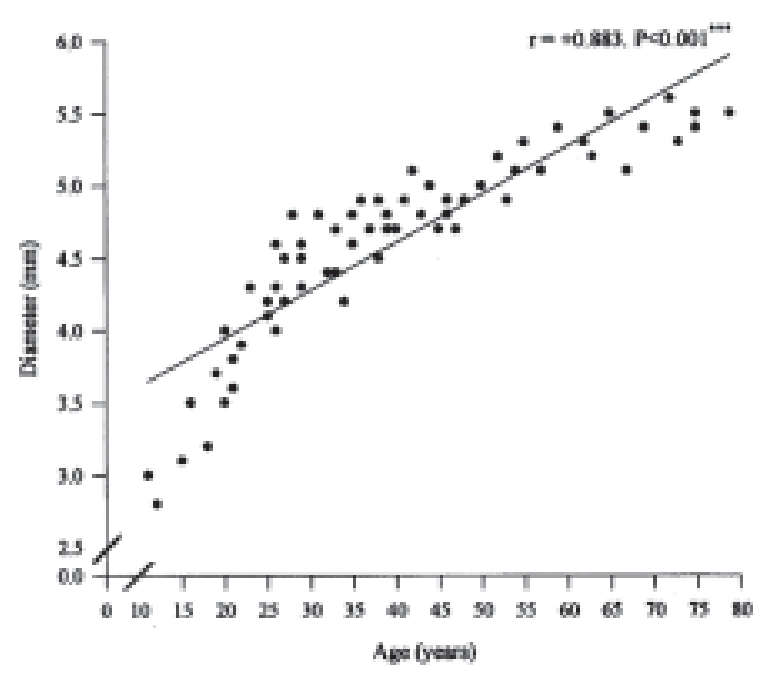

Figure-4: Scatter diagram showing the relationship between age and extra pancreatic part of internal diameter of the main pancreatic duct (MPD) outside the pancreas $(n=65)$

group, A vs F group, A vs G group, B vs E group, B vs $F$ group, $B$ vs $G$ group, $C$ vs $E$ group, $C$ vs $F$ group, $C$ vs $G$ group and D vs E group. The tendency of the internal diameter of the main pancreatic duct prior to independent opening at the duodenum was found to be increased with the advanced age.

In the present study figure: 4 show the statistically significant $(p<0.001)$ positive correlation $(r=0.883)$ between age and internal diameter of the main pancreatic duct out side the pancreas (before joining the common bile duct or prior to independent opening at the duodenum).

The internal diameter of extra pancreatic part of the main pancreatic duct (before joining the common bile duct or prior to independent opening at the duodenum) in all instances found gradually tapered to wards the proximal end.

Stenosis of the main pancreatic duct out side the pancreas just before joining the common bile duct was found in 1 case of group B.

\section{Discussion:}

It is evident from this study that the internal diameter of the main pancreatic duct in the head, body and tail progressively increase with advancing age which was statistically significant $(p<0.001)$ and shows 
positive correlation with age $(r=0.883),(r=849),(r$ $=0.796)$ and $(r=0.688)$ respectively. Millbourn ${ }^{8}$ reported from autopsy and ERCP cases that the internal diameter of the main pancreatic duct increases with age. Larson et $\mathrm{al}^{9}$, Varley et $\mathrm{al}^{6}$ and Magee et $\mathrm{al}^{10}$ described from autopsy roentgenographic study that the pancreatic ductal dilation as normal aging changes. Kim et al ${ }^{11}$ noted a tendency for ductal diameters to be greater in older age group. McCarty et $\mathrm{al}^{12}$ observed the largest diameters of a normal pancreatic duct in a 91 year woman. Axon ${ }^{13}$ said that the duct size varies according to age, sex, size of patient and racial origin, as well as disease. This was suggestive of increasing the internal diameter of the main pancreatic duct progressively with age

Internal diameter of the main pancreatic duct in the head, body and tail described by Birnstingl ${ }^{14}$, Millbourn ${ }^{15}$, Hand $^{16}$, Trapnell and Howard ${ }^{17}$, Magee and Burdick ${ }^{10}$ in autopsy was higher than the present study. They all had measured the ductal internal diameter prior to formol saline fixation. But in this study ductal internal diameter had been measured after 48 hours in 10\% formol saline fixed specimen.

The cadaveric internal diameter of the main pancreatic duct in the head, body and tail described by Berman ${ }^{18}$, Kasugai ${ }^{2}$, Sivak and Sullivan ${ }^{1}$, Varley et $\mathrm{al}^{6}$, Mulholland et $\mathrm{al}^{19}$ and Larson et $\mathrm{al}^{9}$ were similar to the present study. Whereas, Okuda et $\mathrm{al}^{20}$, Ogoshi ${ }^{21}$, Cotton $^{22}$ reported from endoscopic findings was also similar to this study. Newman ${ }^{23}$ measured that the ductal diameters on the basis of an autopsy - roentgenographic study. This was suggestive of similar to this study.

The internal diameter of the main pancreatic duct in the head, body and tail described by Kreel and Sandin $^{24}$, Lawson ${ }^{25}$, Axon ${ }^{13}$, Karim ${ }^{26}$ was lower than the present study. Starling ${ }^{27}$, Classen et al ${ }^{28}$ found that the mean diameter of the pancreatic duct was $0.9 \mathrm{~mm}, 2.03 \mathrm{~mm}$. That was lower than the present study. This dissimilarity may be due to they had chosen the age group up to 60 years.

Limitation of the study:

Females are excluded due to less availability of the female cadaveric pancreas during study period.

\section{References:}

1. Sivak MV Jr., Sullivan BH Jr. Endoscopic retrograde pancreatography: analysis of the normal pancreatogram. Am J Dig Dis. 1976; 21(3): 263-9.

2. Kasugai T, Kuno N, Kobayashi S, Hattori K. Endoscopic pancreatocholangiography. I.The normal. Gastroenterology. 1972; 63(3): 21726.

3. Kune GA. Surgical anatomy of common bile duct. Arch Surg. 1964; 89: 995-1004.

4. Romanes GJ. Cunningham's manual of practical anatomy. Vol. 3. $15^{\text {th }}$ ed. New York: Oxford University Press; 2005. p. 112-5.

5. Morton DA, Peterson KD, Albertine $\mathrm{KH}$. Dissection guide for human anatomy. ed. Edinburgh: Churchill Livingstone; 2004. p.119.

6. Varley PF, Rohrmann CA Jr., Silvis SE, Vennes JA. The normal endoscopic pancreatogram. Radiology. 1976; 118(2): 295-300.

7. Hussain MA. Postmortem study of human heart in Bangladeshi people. [M.Phil. Thesis]. Dhaka: University of Dhaka; 2006.

8. Millbourn E. On the excretory ducts of pancreas in man, with special reference to their relations to each other, to the common bile duct and to the duodenum: radiological and anatomical study. Acta Anat. 1950; 9: 1-34.

9. Larson MM, Panciera DL, Ward DL, Steiner JM, Williams DA. Age-related changes in the ultrasound appearance of the normal feline pancreas. Vater Radiol Ultrasound. 2005; 46(3): 238-42.

10. Magee DJ, Burdick JS. Anatomy, histology, embryology, and development anomalies of the pancreas. In: Feldman M, Friedman LS, Sleisenger $\mathrm{MH}$. editors. Gastrointestinal and Liver Diseases: Pathophysiology, Diagnosis and Management. 7th ed. Philadelphia: W.B. Saunders; 2002: 859-70.

11. Kim HJ, Kim MH, Lee SK, Seo DW, Kim YT, Lee DK, et al. Normal structure, variations, and anomalies of the pancreaticobiliary ducts 
of Koreans: a nationwide cooperative prospective study. Gastrointest Endosc. 2002; 55(7): 889-96.

12. Maccarty RL, Stephens DH, Brown AL Jr., Carlson HC. Retrograde pancreatography in autopsy specimens. Am J Roentgenol. 1975; 123(2): 359-66.

13. Axon AT, Classen M, Cotton PB, Cremci M, Freeny PL, Less WR. Pancreatography in chronic pancreatitis: international definitions. Gut. 1984; 25(10): 1107-12.

14. Birnstingl M. A study of pancreatography. BJS. 1959; 47(202): 128-39.

15. Millbourn E. Calibre and appearance of the pancreatic ducts and relevant clinical problems: a roentgenographic and anatomical study. Acta Chir Scand. 1960; 118: 286-303.

16. Hand $\mathrm{BH}$. An anatomical study of the choledochoduodenal area. BJS. 1963; 50(223): 486-94.

17. Trapnell JE, Howard JM. Transduodenal pancreatography: an improved technique. Surgery. 1966; 60(5): 1112-9.

18. Berman. Anomalous drainage of common bile duct. Arch Surg. 1969; 84: 907-12.

19. Mulholland MW, Moossa AR, Liddle RA. Pancreas: anatomy and structural anomalies. In: Tadataka Yamada. Textbook of Gastroenterology. 2nd ed. Philadelphia: Lippincott;1995: 2051-63.
20. Okuda K, Someya N, Gota A, Kunisaki T, Emura T, Yasumoto M, et al. Endoscopic pancreatography: a preliminary report on technique and diagnostic significance. Am J Roentgenol. 1973; 117: 437-45.

21. Ogoshi K, Niwa M, Hara Y, Nebel OT. Endoscopic pancreatocholangiography in the evaluation of pancreatic and biliary disease. Gastroenterology. 1973; 64: 210-6.

22. Cotton PB. The normal endoscopic pancreatogram. Endoscopy. 1974; 6: 65-70.

23. Newman HF, Weinberg SB, Newman EB, Northup JD. The papilla of Vater and distal portions of the common bile duct and duct of Wirsung. 1958; 106(6): 687-94.

24. Kreel L, Sandin S. Changes in pancreatic morphology associated with aging. Gut. 1973; 14(12): 962-70.

25. Lawson TL, Berland LL, Foley WD, Stewart ET, Geenan JE, Hogan WJ. Ultrasonic visualization of the pancreatic duct. Radiology. 1982; 144: 865-71.

26. Karim M. The study of the comparative anatomy of the pancreas in goats, cows and man. [Thesis]. Dhaka: University of Dhaka; 1994.

27. Starling JA. Significant facts concerning the papilla of Vater. Am J Dig Dis. 1953; 20(5): 124-6.

28. Classen M, Hellwig H, Rosch W. Anatomy of the pancreatic duct: a duodenoscopic radiologic study. Endoscopy. 1973; 514: 14-7. 